\title{
Identification of Malassezia Species Isolated From Patients With Pityriasis Versicolor in Sari, Iran, 2012
}

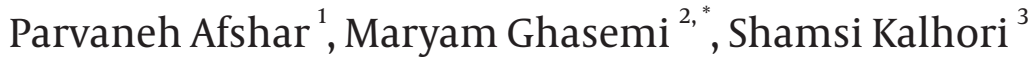 \\ ${ }_{2}^{1}$ Referral Laboratory, Mazandaran University of Medical Sciences, Sari, IR Iran \\ 2 Department of Pathology, School of Medicine, Mazandaran University of Medical Sciences, Sari, IR Iran \\ 3 Mazandaran University of Medical Sciences, Sari, IR Iran \\ ${ }^{*}$ Corresponding author: Maryam Ghasemi, Department of Pathology, School of Medicine Mazandaran University of Medical Sciences, Sari, IR Iran. Tel: +98-1512233010, Fax: +98- \\ 1512234506, E-mail: a.zghasemi@yahoo.com.
}

Received: October 20, 2012; Revised: January 11, 2013; Accepted: February 23, 2013

\begin{abstract}
Background: The genus Malassezia is part of the normal mycota of the skin of humans and other warm-blooded animals as etiological agents of pityriasis versicolor.

Objectives: Several species from the Malassezia genus are known based on morphological, biochemical and molecular approaches. Therefore, the aim of this study was to determine the distribution of Malassezia species in patients with pityriasis versicolor based on morphological, physiological and biochemical criteria in Sari, Iran.

Materials and Methods: In total, among 134 patients clinically suspected of having pityriasis versicolor, attending the Department of Mycology, Boali Sina Hospital and Referral Laboratory of the Mazandaran University of Medical Sciences, 116/134 (86.5\%) positive patients for Malassezia elements, namely, yeast cells and short hyphae in microscopic examination, were included in the study. All 116 samples were inoculated on plates containing modified Leeming and Notman agar medium and identified at species level based on mycological criteria.

Results: However, only 100/116 (86.2\%) or 100/134 (74.6\%) of the patients showed Malassezia spp in culture. Malassezia. globosa (54\%) was the most commonly isolated species followed by M. furfur (32\%), M. slooffiae (6\%), M. restricta (6\%) and M. sympodialis (2\%). Mixed Malassezia species were not identified.

Conclusions: M. globosa was found to be the predominant pityriasis versicolor isolate in Sari, Iran. Since Malassezia species show different responses in their antifungal therapy, thus correct identification of Malassezia species and antifungal susceptibility test could facilitate selection of appropriate antifungal agents.
\end{abstract}

Keywords: Pityriasis versicolor; Malassezia; M. fur fur

\section{Background}

Malassezia yeasts are lipophilic fungi which are regarded as normal flora of the skin, and are recovered in 75-98\% of healthy individuals (1-3). Malassezia yeasts may also have a role in pityriasis versicolor (4), seborrhoeic dermatitis (5, 6), dandruff(6), seborrhoeic blepharitis (7), Malassezia folliculitis (8), confluent, reticulate papillomatosis (9) and uncommon systemic infections. In the last category, Malassezia species are associated with catheter acquired sepsis, fungaemia and pulmonary infection in neonates; these infections can sometimes be life threatening (10-14) and have been reported as significant causes of fungal infections in patients with cancer $(15,16)$ and HIV positive individual (17).

The difficulty in culturing Malassezia spp. in vitro has delayed the determination the taxonomic status of these yeasts. Nowadays, morphological characteristics and physiological features, the use of different Tween com- pounds as well as molecular studies of Malassezia species have allowed their classification into 11 species; $M$. furfur, M. sympodialis, M. slloffiae, M. obtusa, M. globosa, M. restricta, M. pachydermatis, M. yamatoensis, M. nana, M. japonica and $M$. dermatis $(18,19)$. Since molecular methods are not cost effective and unavailable in clinical laboratories, thus the purpose of this study was to identify Malassezia species isolated from pityriasis versicolor patients in Sari, Iran, by conventional methods, based on morphological, physiological and biochemical techniques (20).

\section{Materials and Methods}

\subsection{Sample Collection}

This cross sectional study was conducted between Octobers 2011 to April 2012 and a total of 134 patients clinically suspected of pityriasis versicolor, attending the Department of Mycology, Boali Sina Hospital and Referral Labo-

Implication for health policy/practice/research/medical education :

The results demonstrated a significant relationship between the frequency of Malassezia species and age, however, gender and anatomical site of lesions of pityriasis versicolor was not significant.

Copyright (C) 2013, Ahvaz Jundishapur University of Medical Sciences; Licensee Kowsar Ltd. This is an Open Access article distributed under the terms of the Creative Commons Attribution License (http://creativecommons.org/licenses/by/3.0), which permits unrestricted use, distribution, and reproduction in any medium, provided the original work is properly cited. 
ratory of the Mazandaran University of Medical Sciences were consecutively included. Individuals who received local or systemic antifungal for at least 5 days or corticosteroid agents for 3 weeks before the mycological examination were excluded from the study.

Skin scrapings were taken from the scaliest sites and obtained by the use of sterile blades. The diagnosis of pityriasis versicolor was established by the presence of both hyphae and spores in direct microscopy with $\mathrm{KoH}$ $20 \%$ and methylene blue staining. The assessed samples were plated onto Sabouraud's dextrose agar (SDA, Difco) and modified Leeming and Notman agar $(1 \% \mathrm{w} / \mathrm{v}$ peptone, $1 \% \mathrm{w} / \mathrm{v}$ glucose, $0.2 \% \mathrm{w} / \mathrm{v}$ yeast extract, $0.8 \%$ desiccated ox bile, $0.1 \% \mathrm{v} / \mathrm{v}$ glycerol, $0.05 \% \mathrm{w} / \mathrm{v}$ glycerol monostearate, $0.5 \% \mathrm{v} / \mathrm{v}$ Tween 60 , and $2 \% \mathrm{v} / \mathrm{v}$ oleic acid, $1 \% \mathrm{w} / \mathrm{v}$ agar in distilled water) supplemented with cyclohexamide $(0.5 \%)$ and chloramphenicol (0.05\%)(21), as fungal general medium and incubated at $32^{\circ} \mathrm{C}$ for two weeks in the dark. The study then proceeded as follows, to identify the Malassezia species. This research was approved by the ethics committee of Mazandaran University of Medical Science and written informed consent was obtained from the each participant prior to enrolment.

\subsection{Microscopic and Physiological Characteristics}

Among Malassezia species, only M. pachydermatis is capable of growing on Sabouraud's agar. However, more tests are essential for identification of the remaining $\mathrm{Mal}$ assezia species such as Tween assimilation test, catalase reaction and splitting of esculin. After one week of incubation on modified Leeming and Notman agar at $32^{\circ} \mathrm{C}$, the yeast cells were examined morphologically by gram and methylen blue staining. The catalase reaction was performed by the application of a drop of hydrogen peroxide (30\% solution) onto a culture smear on a glass slide. Production of gas bubbles was considered as a positive reaction. $M$. restricta is the only lipid- dependent species lacking catalase $(22,23)$.

\subsection{Splitting of Esculin}

According to the method described by Mayser et al. (24), the b-glucosidase activity of different Malassezia species was assayed. Briefly, the loop of fresh yeast was deeply inoculated in the esculin agar (Merck, Germany) tube and incubated for 5 days at $32{ }^{\circ} \mathrm{C}$. The splitting of esculin is indicated by darkening of the medium. This test was used to distinguish M. furfur, M. slooffiae and M. sympodialis from other Malassezia species.

\subsection{Tween Assimilation Test}

The ability to utilize individual Tween compounds (Tween 20, 40, 60 and 80) was tested according to Guillot et al. (20). Briefly; the sterile Sabouraud's agar $(16 \mathrm{ml})$ was melted and allowed to cool to approximately $50^{\circ} \mathrm{C}$. Malassezia yeast suspensions (about $10^{5} \mathrm{cfu} / \mathrm{mL}$ ) were mixed with Sabouraud's agar, and the mixtures were plated. Five holes were made in the agar by the means of a $2 \mathrm{~mm}$ diameter punch and filled with $5 \mu$ l of Tween 20, 40, 60 and 80 (Merck, Germany). The plates were incubated for one week at $32^{\circ} \mathrm{C}$. Utilization of Tween was assessed by the degree of growth and /or reaction (precipitation) of the lipophilic yeasts around individual wells.

\subsection{Statistical Analysis}

Data collected in checklists were analyses using SPSS version.16. The data were analyzed using the chi-squared test. A P value of $<0.05$ was considered significant.

\section{Results}

Of the 134 skin scraping samples, 116 patients (86.5\%) were confirmed with pityriasis versicolor, based on the presence of both hyphae and spores in direct microscopy with $\mathrm{KoH} 20 \%$ and methylene blue staining, however, the Malassezia spp. were isolated from100/116 (86.2\%) or 100/134 (74.6\%) patients in the culture media, who were the final enrolled subjects. Table 1 shows that the distribution of patients clinically suspected of pityriasis versicolor based on age/ sex, indicating that there was no significant difference between age and gender of patients with pityriasis versicolor.

Table 1. Distribution of Patients Clinically Suspected of Pityriasis Versicolor Based on Age/Sex

\begin{tabular}{llll}
\hline Age, years & Male No.(\%) & Female No. (\%) & Total No.(\%) \\
\hline $\mathbf{5} 5$ & $4(3)$ & $3(2.2)$ & $7(5.2)$ \\
$\mathbf{6} \mathbf{- 1 4}$ & $1(9.7)$ & $15(11.2)$ & $28(20.9)$ \\
$\mathbf{1 5}-\mathbf{2 4}$ & $20(14.9)$ & $31(23.1)$ & $51(8.1)$ \\
$\mathbf{2 5}-\mathbf{3 4}$ & $16(11.9)$ & $21(15.7)$ & $37(27.6)$ \\
$\mathbf{3 5 - 4 4}$ & $3(2.2)$ & $3(2.2)$ & $6(4.5)$ \\
$\mathbf{2} \mathbf{4 5}$ & $4(3)$ & $1(.7)$ & $5(3.7)$ \\
Total & $60(44.8)$ & $74(55.2)$ & $134(100)$
\end{tabular}

According to descending frequency for the presence of Malassezia species among patients, M. globosa was found in $\mathrm{n}=54 ; 54 \%$ cases, $M$. furfur in $\mathrm{n}=32 ; 32 \%$ cases, $M$. sympodialis in $\mathrm{n}=6 ; 6 \%$ cases, $M$. restricta in $\mathrm{n}=6 ; 6 \%$ cases and $M$. slooffiae in $n=2 ; 2 \%$ cases. In this survey $M$. pachydermatis and $M$. obtusa were not found in any of the cases. There was a significant association between age and Malassezia species frequency $\left(\chi^{2}=36.32 \mathrm{df}=20, \mathrm{P}=0.014\right)$ (Table 2 ). There was no significant association between gender of patients and Malassezia species frequency $\left(\chi^{2}=9.24 \mathrm{df}=\right.$ $4, \mathrm{P}=0.055)($ Table 3$)$. Table 4 has shown the frequency 
Afshar Pet al.

of isolated Malassezia species based on anatomical locations. There was no significant association between ana- tomical sites and Malassezia species frequency $\left(\chi^{2}=23.26\right.$ $\mathrm{df}=20, \mathrm{P}=0.28$ ) (Table 4$)$.

\begin{tabular}{|c|c|c|c|c|c|c|}
\hline Malassezia spp. & M. globosa\% & M. furfur\% & M. sympodialis\% & M. restricta\% & M.slooffiae\% & Total, $\%$ \\
\hline \multicolumn{7}{|l|}{ Age, y } \\
\hline$\leq 5$ & 3 & 1 & 1 & - & - & 5 \\
\hline $6-14$ & 8 & 8 & 1 & 1 & 1 & 19 \\
\hline $15-24$ & 33 & 9 & 2 & 2 & - & 46 \\
\hline $25-34$ & 5 & 13 & 2 & 2 & - & 22 \\
\hline $35-44$ & 3 & - & - & 1 & - & 4 \\
\hline$\geq 45$ & 2 & 1 & - & - & 1 & 4 \\
\hline Total & 54 & 32 & 6 & 6 & 2 & 100 \\
\hline
\end{tabular}

Table 3. Frequency of Malassezia Species According to Gender $(\mathrm{P}=0.055)$

\begin{tabular}{lllllll}
\hline & M. globosa\% & M. furfur\% & M. sympodialis $\%$ & M. restricta\% & M. slooffiae $\%$ & Total, \% \\
\hline Male & 26 & 18 & 4 & - & 2 & 50 \\
Female & 28 & 14 & 2 & 6 & - & 50 \\
Total & 54 & 32 & 6 & 6 & 2 & 100
\end{tabular}

Table 4. Frequency of Malassezia Species According to the Lesion Site $(\mathrm{P}=0.276)$

\begin{tabular}{|c|c|c|c|c|c|c|}
\hline & M. globosa \% & M. furfur\% & M. sympodialis $\%$ & M. restricta \% & M. slooffiae\% & Total , \% \\
\hline Chest & 12 & 8 & - & - & - & 20 \\
\hline Back & 11 & 5 & 3 & 5 & 1 & 25 \\
\hline Abdomen & 14 & 9 & 1 & - & 1 & 25 \\
\hline Neck & 9 & 3 & 1 & - & - & 13 \\
\hline Face & 7 & 4 & 1 & 1 & - & 13 \\
\hline Arms & 1 & 3 & - & - & - & 4 \\
\hline Total & 54 & 32 & 6 & 6 & 2 & 100 \\
\hline
\end{tabular}

\section{Discussion}

Although, Malassezia yeasts are part of the normal flora of the skin and are discovered in $75-98 \%$ of healthy hosts, their association with various skin disorders have been established; many studies have been conducted on the distribution of these yeasts (1-3). A great number of epidemiological studies using culture or molecularbased methods, e.g. PCR-RFLP or nested-PCR, have been performed in different geographical regions in order to investigate Malassezia species in patients with pityriasis versicolor (23, 25-27), including culture-based studies carried out in Spain $(25,28,29)$, Japan (26), Bosnia and Herzegovina (30) Tunisia (27), Iran (31,32), Turkey (33) and India (34).

By using morphological and physiological characteristics particularly in tropical areas, $M$. globosa either alone or associated with other Malassezia spp. (e.g. M. sympodialis, M. slooffiae) was the most commonly isolated Malassezia species. This ratio that indicated the predominance of M. globosa was between 53.3\% and $63.3 \%$ (25-28, 30-35). In contrast, a study carried out by Gupta et al. (36) indicated that M. Sympodialis was the predominant pityriasis versicolor isolate (59.5\%), followed by M. globosa (25.2\%), M. furfur (10.8\%), M. slooffiae (2.7\%), M. restricta (0.9\%) and M. obtusa (0.9\%) in Canada. In the present study, the most predominant species observed was M. globosa (54\%) followed by $M$. furfur (32\%), M. sympodialis (6\%), M. restricta (6\%) and M. slooffiae (2\%). Nevertheless, M. pachydermatitis and $M$. obtuse were not observed from pityriasis versicolor lesions.

Our findings for $M$. globosa were most compatible to that of other similar studies (25, 26, 28, 30-35). However, $M$. furfur and M. slooffiae seemed to occur more frequently than in other studies carried out in Canada (6) Spain $(25,28,35)$, Japan $(26)$ Iran $(28,29)$, Tunusia (27) and Bosnia (25), in which a frequency between $0 \%$ and $25.3 \%$, and $0 \%$ and $5.3 \%$ was reported, respectively. In this study, no significant differences were found in species isolated according to the clinical type or anatomical sites of lesions. 
In contrast, in Bosnia, Prohic et al. (30) and in Spain, Erchiga et al. (25) reported that no significant differences were found in the isolated species according to the clinical sign or anatomical sites of lesions. In this study, the recovery rate of Malassezia spp. from pityriasis versicolor lesions was $74.6 \%(100 / 134)$. In similar studies, this ratio tended to vary between $43.8 \%$ and $91.3 \%$ (17, 25-28, 30-34, 37-40).

It was noted that detection of different ratios of Malassezia species in patients with pityriasis versicolor in different parts of the world could be due to the use of different culture media (Leeming-Notman and modified Dixon agar) (25), climatic regions (tropical, subtropical, etc) (41), different sampling methods (swabbing/scraping) (25) and characteristics of patients (41). Although pityriasis versicolor has worldwide occurrence, its frequency is variable and depends on different climatic, occupational and socio-economic conditions $(42,43)$. In high temperate areas, the disorder is common in young adults aged 17-24 years. In tropical climates, pityriasis versicolor is more common in all age groups, but most cases occur in individuals aged $10-19$ years (39).

In agreement with other investigations $(43,44)$, the highest prevalence of pityriasis versicolor in this study was observed for those aged between 15 to 24 years old, suggesting that the peak of the infection coincided with age periods when the sebum production is atits highest level. The role of gender in propensity to development of pityriasis versicolor is still unclear (29). To date the data revealed that pityriasis versicolor affected male individuals more than females $(45,46)$. However, several studies indicated that the incidence was higher in women (47, 48). In this survey we did not find significant association between gender of infected patients and the frequency of Malassezia species, this may be attributable to the extra attention of both sexes to beauty and skin hygiene (22).

Lesions mostly were found in the neck, face, back, arms, abdomen, and chest and in this survey, the most affected areas were found to be the chest, back and abdomen, which is concordance with the majority of studies worldwide $(17,49)$. The distribution of Malassezia species on the back and chest is proportional to the density and activity of pilosebaceous glands in these areas. However, there are a few reports indicated that pityriasis versicolor lesions can occur in unusual locations such as the nipple, genital areas and groin $(49,50)$.

\section{Conclusions}

According to our data, M. globosa was the main species causing pityriasis versicolor, as it was isolated from 54\% of the lesions; followed by M. furfur (32\% of lesions), while M. pachydermatitis and M. obtuse were not found in any of the cases and in $13.8 \%(16 / 116)$ of patients the culture was negative. The results demonstrated a significant relationship between the frequency of Malassezia species and age, however, gender and anatomical site of lesions of pityria- sis versicolor was not significant. However, more studies with larger samples have to be performed to clarify the investigated subject. Since Malassezia species show different responses to antifungal therapy, thus correct identification of Malassezia species and antifungal susceptibility tests could facilitate selection of appropriate antifungal agents.

\section{Acknowledgements}

The authors are grateful to Dr. Nima Motamed for his help in part of the statistical analysis. We wish to thanks the staff of Boali Sina Hospital and the Referral Laboratory of the Mazandaran University of Medical Sciences.

\section{Authors' Contribution}

None declared.

\section{Financial Disclosure}

None declared.

\section{Funding/Support}

The authors alone are responsible for the content and writing of the paper.

\section{References}

1. Ahn Kyu Joong. Taxonomy of the genus Malassezia. Korean J Med Mycol. 1998;3(2):81-88.

2. Alison SK, Ann GM, Michael PH, Freed-berg IM Eisen AZ, Wolf K, Austen KF, Goldsmith LA, Katz SI. Yeast infection: Candidiasis, Pityriasis (Tinea) versicolor. 2003.

3. Baillon Henri. Treaty fungal medical botany tracking table droguier of the Faculty of Medicine of Paris. O. Doin; 1889.

4. McGinley KJ, Lantis LR, Marples RR. Microbiology of tinea versicolor. Arch Dermatol.1970;102(2):168-71.

5. Bergbrant IM. Seborrhoeic dermatitis and Pityrosporum ovale: cultural, immunological and clinical studies. Acta Derm Venereol Suppl (Stockh). 1991;167:1-36.

6. Bergbrant IM, Johansson S, Robbins D, Scheynius A, Faergemann J, Soderstrom T. An immunological study in patients with seborrhoeic dermatitis. Clin Exp Dermatol.1991;16(5):331-8.

7. Parunovic A, Halde C. Pityrosporum orbiculare. Its possible role in seborrheic blepharitis. Am J Ophthalmol. 1967;63(4):815-20.

8. Borton LK, Schwartz RA. Pityrosporum folliculitis. A common acne form condition of middle age. Arz Med.1981;38:598-601.

9. Kellet JK, Macdonald RH. Confluent and reticulate papillomatosis. Arch Dermatol. 1985;121(5):587-8.

10. Dankner WM, Spector SA, Fierer J, Davis CE. Malassezia fungemia in neonates and adults: complication of hyperalimentation. Rev Infect Dis. 1987;9(4):743-53.

11. Larocco M, Dorenbaum A, Robinson A, Pickering LK. Recovery of Malassezia pachydermatis from eight infants in a neonatal intensive care nursery: clinical and laboratory features. Pediatr Infect Dis J. 1988;7(6):398-401.

12. Mickelsen PA, Viano-Paulson MC, Stevens DA, Diaz PS. Clinical and microbiological features of infection with Malassezia pachydermatis in high-risk infants. J Infect Dis. 1988;157(6):1163-8.

13. Richet HM, McNeil MM, Edwards MC, Jarvis WR. Cluster of Malassezia furfur pulmonary infections in infants in a neonatal intensive-care unit. J Clin Microbiol. 1989;27(6):1197-200.

14. Welbel SF, McNeil MM, Pramanik A, Silberman R, Oberle AD, Midgley G, et al. Nosocomial Malassezia pachydermatis bloodstream infections in a neonatal intensive care unit. Pediatr Infect Dis J.1994;13(2):104-8. 
15. Francis P, Walsh TJ. Approaches to management of fungal infections in cancer patients. Oncology (Williston Park). 1992;6(5):13344.

16. Samonis G, Bafaloukos D. Fungal infections in cancer patients: an escalating problem. In Vivo. 1992;6(2):183-93.

17. Goodman DS, Teplitz ED, Wishner A, Klein RS, Burk PG, Hershenbaum E. Prevalence of cutaneous disease in patients with acquired immunodeficiency syndrome (AIDS) or AIDS-related complex. JAm Acad Dermatol.1987;17(2 Pt1):210-20.

18. Gueho E, Midgley G, Guillot J. The genus Malassezia with description of four new species. Antonie Van Leeuwenhoek. 1996;69(4):337-55.

19. Sugita T, Tajima M, Ito T, Saito M, Tsuboi R, Nishikawa A. Antifungal activities of tacrolimus and azole agents against the eleven currently accepted Malassezia species. J Clin Microbiol. 2005;43(6):2824-9.

20. Guillot J, Guého E, Lesourd M, Midgley G, Chévrier G, Dupont B. Identification of Malassezia species: a practical approach. J Med Mycol.1996;6(3):103-110.

21. Sugita T, Tajima M, Takashima M, Amaya M, Saito M, Tsuboi R, et al. A new yeast, Malassezia yamatoensis, isolated from a patient with seborrheic dermatitis, and its distribution in patients and healthy subjects. Microbiol Immunol. 2004;48(8):579-83.

22. Gupta AK, Kohli Y, Faergemann J, Summerbell RC. Epidemiology of Malassezia yeasts associated with pityriasis versicolor in Ontario, Canada. Med Mycol. 2001;39(2):199-206.

23. Marishita N, Sei Y, Sugita T. Molecular analysis of Malassezia micro flora from patients with pityriasis versicolor. Mycopatholo. 2006;161:61-65.

24. Mayser P, Haze P, Papavassilis C, Pickel M, Gruender K, Gueho E. Differentiation of Malassezia species: selectivity of cremophor EL, castor oil and ricinoleic acid for M. furfur. Br J Dermatol. 1997;137(2):208-13.

25. Crespo Erchiga V, Ojeda Martos A, Vera Casano A, Crespo Erchiga A, Sanchez Fajardo F. Malassezia globosa as the causative agent of pityriasis versicolor. BrJ Dermatol. 2000;143(4):799-803.

26. Nakabayashi A, Sei Y, Guillot J. Identification of Malassezia species isolated from patients with seborrhoeic dermatitis, atopic dermatitis, pityriasis versicolor and normal subjects. Med Mycol. 2000;38(5):337-41.

27. Salah SB, Makni F, Marrakchi S, Sellami H, Cheikhrouhou F, Bouassida S, et al. Identification of Malassezia species from Tunisian patients with pityriasis versicolor and normal subjects. Mycoses. 2005;48(4):242-5.

28. Aspiroz C, Ara M, Varea M, Rezusta A, Rubio C. Isolation of Malassezia globosa and M. sympodialis from patients with pityriasis versicolor in Spain. Mycopathologia. 2002;154(3):111-7.

29. Lacaz C da S, Porto E, Martins JE Costa, Heins-Vaccari EM, Takahashi de Melo N. Treaty of medical mycology. J Ins Trop Med São Paulo. 2002;44(5):297-298.

30. Prohic A, Ozegovic L. Malassezia species isolated from lesional and non-lesional skin in patients with pityriasis versicolor. Mycoses. 2007;50(1):58-63.

31. Rasi A, Naderi R, Behzadi AH, Falahati M, Farehyar S, Honarbakhsh Y, et al. Malassezia yeast species isolated from Iranian patients with pityriasis versicolor in a prospective study. Mycoses. 2010;53(4):350-5.
32. Tarazooie B, Kordbacheh P, Zaini F, Zomorodian K, Saadat F, Zeraati $\mathrm{H}$, et al. Study of the distribution of Malassezia species in patients with pityriasis versicolor and healthy individuals in Tehran, Iran. BMC Dermatol. 2004;4:5.

33. Karakas M, Turac-Bicer A, Ilkit M, Durdu M, Seydaoglu G. Epidemiology of pityriasis versicolor in Adana, Turkey. J Dermatol. 2009;36(7):377-82.

34. Dutta S, Bajaj AK, Basu S, Dikshit A. Pityriasis versicolor: socioeconomic and clinico-mycologic study in India. Int J Dermatol. 2002;41(11):823-4.

35. Erchiga V Crespo, Martos A Ojeda, Casaño A Vera, Erchiga A Crespo, Fajardo F Sanchez, Guého E. Mycology of pityriasis versicolor. 2008.

36. Gupta AK, Kohli Y, Summerbell RC, Faergemann J. Quantitative culture of Malassezia species from different body sites of individuals with or without dermatoses. Med Mycol. 2001;39(3):24351.

37. Gaitanis G, Velegraki A, Alexopoulos EC, Chasapi V, Tsigonia A, Katsambas A. Distribution of Malassezia species in pityriasis versicolor and seborrhoeic dermatitis in Greece. Typing of the major pityriasis versicolor isolate M. globosa. $\mathrm{Br} J$ Dermatol. 2006;154(5):854-9.

38. Gaitanis G, Velegraki A, Frangoulis E, Mitroussia A, Tsigonia A, Tzimogianni A, et al. Identification of Malassezia species from patient skin scales by PCR-RFLP. Clin Microbiol Infect. 2002;8(3):16273.

39. Iskit S, Ilkit M, Turc-Bicer A, Demirhindi H, Turker M. Effect of circumcision on genital colonization of Malassezia spp. in a pediatric population. Med Mycol. 2006;44(2):113-7.

40. Leeming JP, Notman FH. Improved methods for isolation and enumeration of Malassezia furfur from human skin. J Clin Microbiol. 1987;25(10):2017-9.

41. Gupta AK, Batra R, Bluhm R, Boekhout T, Dawson TL, Jr. Skin diseases associated with Malassezia species. J Am Acad Dermatol. 2004;51(5):785-98.

42. Borelli D, Jacobs PH, Nall L. Tinea versicolor: epidemiologic, clinical, and therapeutic aspects. J Am Acad Dermatol. 1991;25(2 Pt1):300-5.

43. Sunenshine PJ, Schwartz RA, Janniger CK. Tinea versicolor. Int J Dermatol.1998;37(9):648-55.

44. Midgley G, Gueho E, Guillot J. Disease caused by Malassezia species. 9 ed. 4. London: Arnold; 1998.

45. Belec L, Testa J, Bouree P. Pityriasis versicolor in the Central African Republic: a randomized study of 144 cases. J Med Vet Mycol. 1991;29(5):323-9.

46. Prohic A. Identification of Malassezia species isolated from scalp skin of patients with psoriasis and healthy subjects. Acta Dermatovenerol Croat. 2003;11(1):10-6.

47. Gupta AK, Bluhm R, Summerbell R. Pityriasis versicolor. J Eur Acad Dermatol Venereol. 2002;16(1):19-33.

48. Nikpoor N, Buxton MW, Leppard BJ. Fungal diseases in Shiraz. Pahlavi Med J.1978;9(1):27-49.

49. Rudolph RI, Holzwanger JM. Letter: Inverse tinea versicolor. Arch Dermatol.1975;111(9):1213.

50. Burkhart CG, Dvorak N, Stockard H. An unusual case of tinea versicolor in an immunosuppressed patient. Cutis. 1981;27(1):56-8. 